\title{
¿CUÁNTO IMPORTA LA SALUD DE LAS MUJERES? CUIDADOS DE LA MATRONERÍA EN TIEMPOS DE PANDEMIA
}

\section{How Much Does Women's Health Matter? Midwifery Care in a Pandemic}

Augusto Obando-Cid ${ }^{1}$, Josselyn González-Gómez ${ }^{2}$, Araceli Saavedra-Sepúlveda ${ }^{3}$, Olga Vásquez-Palma ${ }^{4}$, Elga Arroyo-Cortes ${ }^{5}$

Autor correspondencia: Dr. Augusto Obando-Cid.

Correo electrónico: augusto.obando@ufrontera.cl

1. Matrón; Magíster en Ciencias Sociales Aplicadas; Doctor en Procesos Sociales y Políticos en América Latina; Doctor en Ciencias Sociales. Departamento de Salud Pública. Facultad de Medicina, Universidad de La Frontera. (Temuco, Chile)

2. Matrona; Magíster (c) en Epidemiología Clínica. Escuela de Obstetricia y Puericultura. Facultad de Ciencias, Universidad Mayor. (Temuco, Chile)

3. Matrona; Magíster (c) en Epidemiología Clínica. Departamento de Salud Pública. Facultad de Medicina, Universidad de La Frontera. (Temuсo, Chile)

4. Antropóloga; Magíster en Educación; Doctora en Ciencias Sociales. Departamento de Procesos Terapéuticos. Facultad de Ciencias de la Salud. Universidad Católica de Temuco. (Temuco, Chile)

5. Matrona; Magister en Ciencias Sociales Aplicadas. Presidenta de la Sociedad Científica Chilena de Matronas y Matrones (SOCIECHIMA). (Temuco, Chile)

Recibido: 16/06/2021 Aceptado: 10/01/2022 


\section{RESUMEN}

INTRODUCCIÓN Y OBJETIVOS. En Chile, los servicios de salud se abocaron al control de la Pandemia por COVID-19, tomando medidas extraordinarias e inmediatas, priorizando algunas prestaciones y postergando otras atenciones de salud. Desde ahí surge la interrogante sobre cómo se enfrentan los cuidados de salud sexual y reproductiva en el sistema de salud chileno en el contexto de pandemia, desde la perspectiva de los profesionales de la Matronería en la región de La Araucanía. Los objetivos que guían el presente estudio son: describir el abordaje de la atención en salud sexual y salud reproductiva en Chile en tiempos de pandemia por COVID- 19 y explorar los cuidados y prioridades de la atención de matronería. MATERIAL Y MÉTODO. El estudio enmarcado en el paradigma complejo, con un enfoque fenomenológico y exploratorio, usando la técnica de entrevista abierta. Las/los participantes, profesionales de la matronería en funciones formativas y de atención clínica a usuarias dentro del Sistema de Salud Chileno, seleccionados por conveniencia. El análisis de los datos se realizó desde la perspectiva de la Teoría Fundamentada. RESULTADOS Y CONCLUSIONES. Como hallazgo surge la postergación ocurrida en los cuidados de la atención en matronería y la adaptabilidad adoptada por este estamento en los diferentes niveles de atención para mantener su compromiso con la salud de las mujeres. Se concluye que los cuidados de la salud sexual y salud reproductiva siempre han estado invisibilizados en la «domesticación de su entrega» y altamente feminizados, que los hace prescindibles por el sistema de salud.

Palabras clave: pandemia; matronería; calidad de los cuidados en salud; continuidad de los cuidados.

\section{ABSTRACT}

INTRODUCTION AND AIMS. In Chile, health services focused on controlling the COVID-19 pandemic, taking extraordinary and immediate measures, prioritizing some benefits and postponing other health care. From there, the question arises about how sexual and reproductive health care is faced in the Chilean health system in the context of the pandemic, from the perspective of midwifery professionals in the Araucanía region. The objectives that guide this study are: To describe the approach to sexual and reproductive health care in Chile in times of COVID-19 pandemic and to explore the care and priorities of midwifery care. MATERIAL AND METHOD. The study framed in the complex paradigm, with a phenomenological and exploratory approach, using the open interview technique. The professional participants of the midwifery in formative functions and clinical attention to users within the Chilean Health System, selected for convenience. The analysis of the data was carried out from the perspective of grounded theory. RESULTS AND CONCLUSIONS. As a finding arises the postponement occurred in the care of care in midwifery and the adaptability adopted by this sector in the different levels of care to maintain its commitment to the health of women. It is concluded that sexual and reproductive health care has always been invisible in the "domestication of its delivery" and highly feminized, which makes them dispensable by the health system.

Keywords: Pandemic; Midwifery; Quality of Health Care; Continuity of Care. 


\section{INTRODUCCIÓN}

Los coronavirus $(\mathrm{CoV})$ son una amplia familia de virus que pueden causar diferentes síntomas, desde el resfriado común hasta enfermedades más graves (OMS, 2020). A finales del año 2019 comenzó un brote infeccioso de neumonía por coronavirus proveniente de Wuhan, China, de difícil control, correspondía a una nueva cepa de coronavirus que no se había encontrado antes en el ser humano que fue nombrada oficialmente como SARS CoV-2 por el comité internacional de taxonomía de virus, mientras que la enfermedad manifestada por este virus se denominó «COVID-19» (OMS, 2020). Consecuentemente, científicos se abocaron a realizar minuciosos estudios para poder combatirlo, generándose paulatinamente nuevos avances para prevenirlo y poder tratarlo, como es el caso de las diversas vacunas desarrolladas.

Ningún país se encontraba preparado para este escenario epidemiológico, por ello los servicios de salud a nivel mundial se han visto colapsados para responder a esta pandemia, significando un nuevo reto para los sistemas de salud, pero, sobre todo, desafiando al personal sanitario en el manejo de estresores clínicos y no clínicos. Cabe mencionar que algunos de los estresores son producto de la escasez de equipos de protección personal, la mortalidad y morbilidad asociadas a esta enfermedad, la cobertura de la atención en otras especialidades o servicios de salud, además del temor de llevar el virus a los miembros de la familia y la realidad de perder algún compañero de trabajo por el COVID-19 (Hu et al., 2020; Zerbini et al., 2020; Lai et al., 2020; Lu et al., 2020; Kang et al., 2020).

En Chile, las primeras comunas que ingresaron a cuarentena para el control del virus lo hicieron el 29 de marzo, a 13 días de la llegada del primer caso al país. Dentro de estas comunas se encontraban Temuco y Padre las Casas, en la región de La Araucanía, considerada la región más pobre del país (Ministerio de Desarrollo Social, 2017), con alta concentración de población rural y Mapuche (Instituto Nacional de Estadísticas (INE) 2017).

Paulatinamente, se fueron sumando otras comunas de la región, tales como Victoria, Angol y Nueva Imperial (Ministerio de Salud, 2020). Sin duda, este escenario tan inmediato llevó a los servicios de salud de la región a tomar medidas decisivas y en un corto plazo para el control del virus, priorizando prestaciones de salud y siguiendo los escasos lineamientos dictados a nivel central (Colegio Médico de Chile, 2020). 
La Pandemia de COVID 19, en el contexto chileno, no solo ha develado las problemáticas asociadas a un sistema de salud debilitado por el asalto neoliberal (Labra, 2002), sino que, además, permite observar que este modelo construye y reproduce complejas situaciones de desigualdades sociales que terminan generando inequidades en salud.

Dado lo anterior, se puede afirmar que el modelo neoliberal desde su implementación a fines de los años setenta e inicios de los ochenta (Labra, 2002), ha generado crecimiento económico y acumulación de la riqueza concentrada en un sector minoritario de la ciudadanía, lo que ha dejado al grueso de la población sobreendeudada y sin acceso a los derechos básicos. Aquello finalmente tensionó el sistema social de tal manera que, al acentuar las profundas fisuras de la desigualdad con un alza menor de pasajes del metro, produjo una fuerte y sostenida reacción que se ha denominado «estallido social», iniciada el 18 de octubre del año pasado, donde gran parte de la población chilena hizo eco del malestar general y de la demanda de derechos básicos, entre ellos la salud (Mira S., 2011; Silva-Peña y Paz-Maldonado, 2019). Este último, en tanto derecho, fue reducido a libertad de elección entre prestadores, generando así profundas transformaciones en el sistema de salud chilena iniciados en la década de los ochenta, que llevó a su privatización y la continua pauperización y desmantelamiento del sector público, además de una escisión entre la atención primaria en salud (APS) y los niveles de mayor complejidad (Homedes y Ugalde, 2002).

Es por ello por lo que, aparejado al desmantelamiento del sistema público de salud, también se vio desmantelada la red de cuidados, generando en última instancia la transformación material y subjetiva de las relaciones sociales, tanto intra como extrasistema de salud, y en la sociedad chilena toda, podríamos enunciar una «crisis de los cuidados» por la neoliberalización de la existencia.

Es en este marco contextual donde observamos un sinnúmero de transformaciones en lo referente a los cuidados, que según Tronto deben entenderse como:

Una actividad humana que incluye todo lo que hacemos para mantener, continuar y reparar nuestro 'mundo' para que podamos vivir en él lo mejor posible. Ese mundo incluye nuestros cuerpos, nosotros mismos y nuestro entorno, todo lo cual buscamos entrelazar en una red compleja que sustenta la vida. (1993, p. 103)

En este contexto, cuando se plantea el estudio de los cuidados, se relevan las transformaciones con relación al reordenamiento de estos, debido al capitalismo en clave 
neoliberal, donde por un lado emergen las oportunidades laborales asociadas a la provisión de cuidados que van desde servicios domésticos, de ayuda en el espacio domiciliario, o en instituciones para el cuidado como guarderías, hospitales y geriátricos, que son ocupadas por mujeres pobres o migrantes; y por otro para quienes prestan tales servicios de cuidados remunerados, se encuentran sometidas a la doble o triple jornada laboral, o a la sobrecarga de la red de apoyo. Las anteriores transformaciones sitúan a las mujeres tanto dentro y fuera de las familias como las que mayoritariamente se están encargando de dar respuesta a las necesidades de cuidado directamente, o bien organizando su provisión a través de recursos públicos o del mercado (Palomo, 2009).

Es en esta lógica donde es necesario plantear el uso del término «domesticación del trabajo» (Palomo, 2009, p. 15), qué está relacionado con la feminización de este y que desde la perspectiva de Donna Haraway:

El trabajo, Independientemente de que lo lleven a cabo hombres o mujeres, está siendo redefinido como femenino y feminizado. El término «feminizado» significa ser enormemente vulnerable, apto a ser desmontado, vuelto a montar, explotado como fuerza de trabajo de reserva, estar considerado más como servido: que como trabajador, sujeto a horarios intra y extrasalariales que son una burla de la jornada laboral limitada. (1995, p. 284)

La noción de domesticación pretende superar la dualidad femenino-masculino y pensar estas transformaciones a partir de las cualidades, condiciones y ámbitos en las que operan, sin obviar el hecho de que son mujeres las que se encuentran en el centro de estos procesos, con el fin de renovar el concepto de trabajo y englobar en él una gran cantidad de actividades que han realizado y realizan las mujeres en el ámbito de los cuidados que son centrales.

Es por ello por lo que, dentro de esta transformación del trabajo, su feminización y domesticación, es necesario releer y analizar los contextos y procesos de los cuidados en el campo de la salud, el cual, además de feminizado, reproduce y produce formas de cuidado específicas para mantener y recuperar la salud, tratar la enfermedad y acompañar a la muerte, generando por momentos difusos bordes entre el espacio familiar doméstico y el espacio institucionalizado del centro de salud, dándose una suerte de dialéctica con relación a la institucionalización del hogar y la domesticación del centro de salud.

En esta misma lógica emergen los cuidados en matronería, los cuales están basados en prácticas de cuidado hacia mujeres y familias desde una perspectiva biopsicosocial 
(Powell Kennedy, 1995), además de biomédica (MacDorman y Singh, 1998), cuyos efectos tienen estrecha relación en la salud reproductiva, sexual y perinatal. Dado que el foco del cuidado son las mujeres, y en la gran mayoría de los casos son mujeres quienes otorgan el cuidado, podemos plantear que en estricto rigor se configura el hecho de que, en el centro del vínculo del cuidado, son mujeres cuidando de mujeres, con todas las ventajas que ello conlleva, pero además con todo el peso estructural y sistémico de la feminización y domesticación, basado en desigualdades e inequidades instaladas desde lo social en el sistema de salud.

En la actualidad, a nivel internacional, el cuidado en matronería se plantea en términos de una formación integral que abarca el mejor cuidado para las mujeres, basado en un modelo integral de cuidados, fundamentado en la continuidad de la atención integrando todas las necesidades biopsicosociales de las mujeres, pareja y familia (Gamble et al., 2020), lo cual genera efectos en la salud, produciendo salud y recuperando la salud en mujeres (Mathias, Davis y Ferguson, 2020), inclusive en los momentos actuales de pandemia de COVID 19 (Renfrew et al., 2020).

En el contexto chileno, este cuidado de matronería se observa en relación con el cuidado al proceso reproductivo, en todos sus ámbitos, pero con especial énfasis en el parto respetado (Binfa et al., 2011; 2016), pero desde finales de la década de los noventa, los cuidados han desbordado el proceso reproductivo y se han expandido hacia la salud sexual, la salud reproductiva y la salud perinatal (Lillo et al., 2016).

Es por ello por lo que finalmente podemos preguntarnos: ¿Cómo se enfrentan los cuidados de salud sexual y salud reproductiva en el sistema de salud chileno en el contexto de pandemia, desde la perspectiva de los profesionales de la Matronería desde La Araucanía? Siendo los objetivos de la presente investigación describir el abordaje de la atención en salud sexual y salud reproductiva en Chile en tiempos de pandemia por COVID- 19 y explorar los cuidados y prioridades de la atención de matronería.

\section{MATERIAL Y MÉTODO}

En el marco de una metodología cualitativa, el estudio se sitúa en el paradigma de la complejidad (Morin, 2009), en el sentido de considerar al ser humano como multidimensional, posible de abordar desde una perspectiva física-bio-antropológica, integral y multidisciplinaria. Además, desde un enfoque fenomenológico, con un diseño exploratorio (Creswell y Creswell, 2018; Creswell y Poth, 2018). 
Para la construcción de datos, se utilizó la técnica de entrevista abierta, aplicada por una única investigadora especialista en entrevista cualitativa, vía online a través de las plataformas Zoom o Meet, con una duración aproximada de entre 45 a 60 minutos, con una media de duración de 50 minutos, realizándose todas ellas en un periodo de un mes. Solo en dos entrevistas se generó un problema de conexión, que fue subsanado dentro del tiempo destinado para su realización, sin mayores inconvenientes. Las entrevistas abiertas están sustentadas en un guion básico conducido por el objetivo de estudio, basado en las siguientes dimensiones: a) manejo general de la pandemia, b) cuidados de matronería en pandemia, c) cuidado en salud sexual y salud reproductiva. Las preguntas formuladas fueron muy abiertas, ya que la premisa principal fue escuchar las posiciones de los y las participantes, tomándose notas de campo respecto a su lenguaje no verbal y su contexto. Aquello permitió abarcar las dimensiones del fenómeno necesarias de analizar, para comprender cómo se enfrentan los cuidados de la salud sexual y reproductiva en el contexto del desarrollo de la pandemia, el manejo y respuesta de las instituciones desde la perspectiva de las y los profesionales matronas y matrones. La saturación de datos ocurrió cuando se evidenció la imposibilidad de generar nuevas categorías conceptuales y sujetos sociológicos (Berteaux, 2005).

Para el registro se realizó una grabación de audio, posteriormente se transcribió la entrevista, generando una base de datos, la cual fue gestionada a través del software Atlasti en su versión 8. Se debe destacar que se realizó una devolución a las participantes en una jornada online vía Zoom dando a conocer los resultados preliminares. Asimismo, cada participante tuvo acceso a la transcripción íntegra de su entrevista para realizar alguna retroalimentación, permitiendo agregar nuevos elementos a esta o rectificando algunas ideas planteadas por las/los participantes previamente. Por último, terminada la investigación, después de haber obtenido los resultados, se procedió a realizar el proceso de validación solicitada, reuniéndonos con las organizaciones de participantes para presentarles los resultados, quienes los aprobaron y solicitaron su divulgación científica.

Las y los participantes de la investigación fueron matrones y matronas en funciones formativas docentes y de atención clínica a usuarias. El proceso de acceso a la muestra se inició con el envío de una invitación por correo electrónico a participar en el estudio, tanto al Colegio de Matronas y Matrones Regional, como a las socias/los socios de la Sociedad Científica Chilena de Matronas y Matrones «SOCIECHIMA»; estas dos entidades fueron quienes la difundieron a través de sus bases de datos. A continuación, las matronas y 
matrones interesadas/os en participar voluntariamente contactaron por vía correo electrónico y telefónica con las y los investigadores, conformándose de este modo el muestreo de voluntarios. Posteriormente, se utilizó un muestreo por conveniencia para profundizar en el proceso de muestreo cualitativo, estableciéndose así los criterios de inclusión, los cuales fueron: a) tener domicilio y trabajar en la Región de La Araucanía; b) manifestar a través de la firma de un consentimiento informado; c) el interés personal voluntario de participar. Por su parte, los criterios de exclusión fueron: a) contar con menos de 3 años de ejercicio profesional; b) que se desempeñen fuera de la región de la Araucanía; c) no contar con una adecuada conexión a internet; d) y negarse a la firma del consentimiento informado. Se conformó finalmente una muestra cualitativa de 18 participantes que cumplían los criterios de inclusión y exclusión (ver Tabla 1).

Tabla 1. Caracterización de las/los participantes

\begin{tabular}{|l|l|l|}
\hline Participante & Sexo & Nivel de atención \\
\hline Entrevistad* 1 & mujer & Nivel Terciario (Hospital) \\
\hline Entrevistad* & hombre & Nivel Primario (APS) \\
\hline Entrevistad* 3 & mujer & Nivel Terciario (Hospital) \\
\hline Entrevistad* 4 & mujer & Nivel Terciario (Hospital) \\
\hline Entrevistad* 5 & mujer & Nivel Terciario (Hospital) \\
\hline Entrevistad* 6 & mujer & Nivel Terciario (Hospital) \\
\hline Entrevistad* 7 & mujer & Nivel Terciario (Hospital) \\
\hline Entrevistad* 8 & mujer & Nivel Terciario (Hospital) \\
\hline Entrevistad* 9 & mujer & Nivel Terciario (Hospital) \\
\hline Entrevistad* 10 & mujer & Nivel Primario (APS) \\
\hline Entrevistad*11 & mujer & Nivel Primario (APS) \\
\hline Entrevistad* 12 & hombre & Nivel Primario (APS) \\
\hline Entrevistad* 13 & Docencia Universitaria \\
\hline Entrevistad* 14 & & Nivel Primario (APS) \\
\hline
\end{tabular}




\begin{tabular}{|l|l|l|}
\hline Entrevistad*15 & mujer & Nivel Primario (APS) \\
\hline Entrevistad* 16 & mujer & Nivel Primario (APS) \\
\hline Entrevistad* 17 & mujer & Nivel Primario (APS) \\
\hline Entrevistad* 18 & hombre & Nivel Primario (APS) \\
\hline
\end{tabular}

Fuente: Elaboración propia

Las unidades de observación se componen de frases extraídas de los relatos de las y los entrevistadas/os. Las variantes discursivas de las entrevistadas y entrevistados producidas en el estudio fueron analizadas desde la perspectiva de la Teoría Fundamentada (Charmaz, 2013; Requena, Carrero y Soriano, 2006; Clarke, 2005), donde las categorías se encuentran en estrecha relación con la pregunta y objetivos de investigación, mientras que las subcategorías emergen del análisis de los discursos de las/los profesionales participantes.

\section{Aspectos Éticos}

Los aspectos éticos y legales de la presente investigación se fundamentan en la Ley 20.120 sobre la investigación científica en el ser humano, su genoma y que prohíbe la clonación humana (MINSAL, 2006) y la Ley 20.584, que regula los derechos y deberes que tienen las personas en relación con acciones vinculadas a su atención en salud (MINSAL, 2012), donde en este caso son relevantes los aspectos referentes a la solicitud de consentimiento informado, la protección de la identidad y la clasificación del estudio; de acuerdo con sus implicaciones para con la integridad de los sujetos participantes, se plantea que la presente investigación no vulnera su integridad. Por otra parte, se declara expresamente que en la presente investigación la participación fue voluntaria, ofreciendo claramente a las/los participantes la posibilidad de abandonar el estudio cuando ellas/ellos quisieran. Además, se realizó la entrega del consentimiento informado por vía correo electrónico, previo a la realización de la entrevista, para su lectura, aprobación y firma, el cual, se indicó a las/los participantes, debía ser remitido por la misma vía al equipo investigador para su recepción y custodia, manteniéndose en resguardo por el investigador principal del presente estudio. Además, al inicio de la entrevista, se corroboraba nuevamente el deseo de participación y se consultaba si había dudas o la necesidad de aclaraciones sobre el documento del consentimiento informado. 
Se garantizó la confidencialidad de los y las participantes resguardando y protegiendo la identidad de entrevistadas y entrevistados y el contenido de las entrevistas, siendo de uso exclusivo para la presente investigación, no recabando datos sensibles de los participantes, por lo cual es considerada de bajo riesgo. El equipo de investigadoras/es durante el proceso de análisis custodió las grabaciones y resguardó la identidad de las/los participantes a través de un código asignado a cada entrevistada/a. Además, el proceso de transcripción fue fiel a la grabación electrónica, guardándose dicho registro durante la duración de la investigación, para luego ser eliminada.

\section{RESULTADOS}

Los dos grandes temas que guían la presente investigación tienen relación con a) el abordaje de la atención en salud sexual y salud reproductiva en Chile en los tiempos de pandemia y b) los cuidados y prioridades en la atención de matronería.

Por otra parte, las categorías asociadas a los objetivos de la presente investigación son: a) el manejo general de la pandemia; b) postergación de los cuidados de la salud sexual y reproductiva; c) cuidados de la atención y d) gestión de los cuidados en matronería.

Desde el relato de las entrevistadas y entrevistados, emergen las subcategorías que son presentadas en el siguiente esquema (ver Esquema 1).

\section{TEMA 1: Abordaje de la atención en salud sexual y salud reproductiva en Chile en tiempos de Pandemia por COVID-19}

\section{Categoría 1: Manejo general de la pandemia}

Esta categoría incorpora opiniones relacionadas con la respuesta de las instituciones del Estado frente a la pandemia, el manejo de autoridades de salud y también la conducta de la población. En general, las/os participantes del estudio toman distancia de su propia vivencia para evaluar el manejo, las decisiones adoptadas por el nivel central del sistema de salud y su aplicación en terreno. Además, presentan una postura crítica respecto al comportamiento de la población. 
Esquema 1. Matriz de resultados. Cuidados de Matronería en tiempos de pandemia por COVID-19

Temas

Categorías

Subcategorías

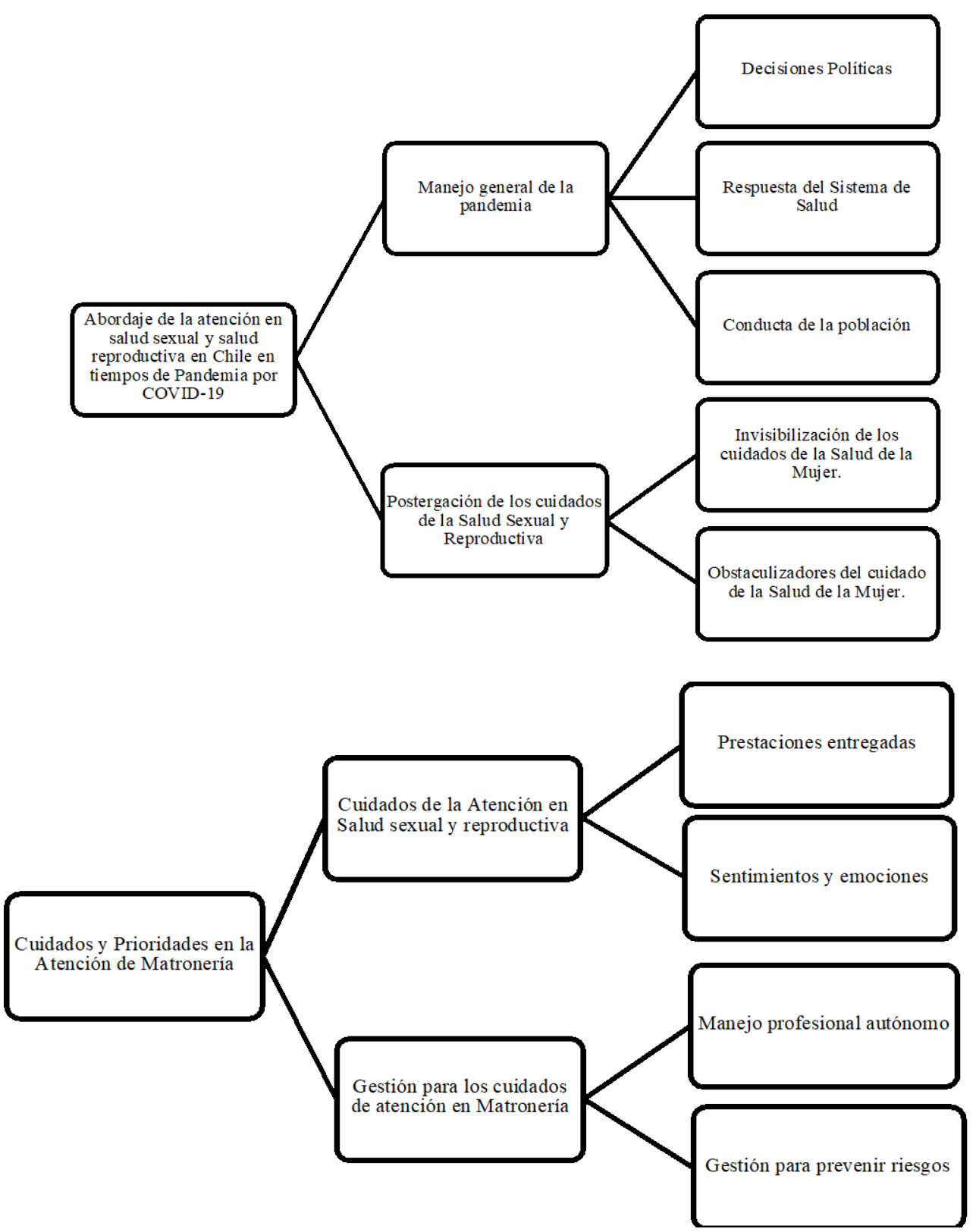

Fuente: elaboración propia para el presente estudio. 


\section{Subcategoría "Decisiones políticas"}

Esta subcategoría emerge de las afirmaciones que realizan las/los participantes del estudio en relación con la gestión general de la pandemia en el país. Algunas aseveraciones son: «La verdad considero que las medidas no han sido lo suficientemente rigurosas desde un principio, creo que las autoridades con las medidas tomadas hasta el momento, estamos lejos de poder controlar lo que está pasando» (E-6); «Me parece que quienes dirigen el país les faltó reflexión y humildad, para entender la magnitud del problema sanitario. No incorporaron aprendizajes de países que partieron antes con la pandemia» (E-9).

Por otro lado, se observa que perciben un buen manejo de la gestión. Estas respuestas son: «Sinceramente, siento que se han realizado estrategias adecuadas, no soy muy crítica ya que comprendo que nunca nos hemos enfrentado a una pandemia de estas características continuamente se van cambiando, para ofrecer mayores garantías» (E-2).

\section{Subcategoría «Respuesta del Sistema de Salud»}

Esta subcategoría surge de las respuestas de participantes en el estudio, acerca de las medidas y accionar de Autoridades del MINSAL, jefaturas directas y funcionariado en general. Las opiniones son diversas. Algunas expresan descontento: «[...] siento que el flujo de la información sobre los cambios realizados se ha tomado sin considerar la opinión de los funcionarios que trabajamos en los servicios dónde se han producido estos cambios» (E-8).

Otras percepciones se refieren al compromiso en el actuar de directivos y funcionariado del sector salud: «En este contexto, he visto que tanto directivos como funcionarios de los diferentes servicios de nuestra institución, han hecho grandes esfuerzos para dar respuesta a las necesidades y demandas que ha generado la pandemia, mostrando gran compromiso y espíritu de servicio» (E-5).

\section{Subcategoría "Conducta de la población»}

La conducta de la población en tiempo de pandemia es mencionada en varias ocasiones, siendo evaluada como responsable, y en este grupo se menciona a las mujeres gestantes, quienes, dado esa condición, toman medidas preventivas y su círculo cercano las «cuidan más». Algunas aseveraciones son: «[...] y con respecto de la embarazada, ellas se familiarizan más con el autocuidado, pues tanto ellas como el circulo, piensan en la protección a dos vidas, por lo que al aislarse generalmente evitan el Contagio Masivo» (E-18); «[...] la población femenina ha tomado algo de conciencia, lo que se evidencia 
en el número de consultas diarias en urgencias, las cuales han disminuido y por tanto repercute en el bienestar de las familias de nuestras usuarias» (E-14).

A su vez, otras conductas se consideran irresponsables: «Pienso que el mayor problema es la falta de toma de conciencia de la población, en las medidas básicas de cuidado y distanciamiento social, tanto usuarios como personal de salud» (E-13).

\section{Categoría 2: Postergación de los cuidados de la salud sexual y reproductiva}

Se refiere a la percepción de matronas y matrones de que la atención en salud sexual y salud reproductiva no es prioridad en ningún momento para el sistema de salud.

\section{Subcategoría «Invisibilización de los cuidados de la Salud de la Mujer»}

Se refiere a los relatos de profesionales de la Matronería en relación con la centralización total de la atención en salud, monopolizando todos los esfuerzos humanos, físicos y económicos de forma unitemática. Una situación que impactó en la postergación de las atenciones que no se detienen, como el proceso reproductivo, las urgencias ginecológicas y obstétricas, entre otros atingentes a la salud de la Mujer. Algunas respuestas donde señalan que no han sido priorizados son: «Percibo además que no logramos otorgar cobertura adecuada a nuestras usuarias... se están sintiendo abandonadas» (E-17); «Me parece que las medidas han sido insuficientes, y se ha dejado completamente de lado la atención de la salud sexual y reproductiva» (E-16); «Siento que somos el eslabón olvidado del Sistema de Salud, en desmedro de la Salud de la Mujer» (E-11); «[...] Las estrategias y protocolos para el programa de la salud de la mujer, simplemente no ha llegado» (E15); «APS y lo que involucra la atención a la ciudadanía en salud sexual y reproductiva ha quedado sin prioridad (E-10).

Otros relatos enfatizan la postergación de los cuidados del proceso reproductivo: «Considero que no se ha dado la importancia a la gestante, más aún al binomio madre e hijo. Tampoco estuvo disponible los test Covid 19 para nuestras mujeres en trabajo de parto» (E-3); «Siento que la atención más perjudicada es la que le damos a la gestante en trabajo de parto, ya que se encuentra sin acompañamiento hasta el alta, en un momento crucial de su vida, estar sola es muy perjudicial» (E-4); «Siento que en general la maternidad de mi establecimiento ha sido dejada de lado por los directivos» (E-5). 


\section{Subcategoría «Obstaculizadores del cuidado de la Salud de la Mujer»}

Esta subcategoría emerge de las/los participantes cuando señalan la falta de elementos de protección personal (EPP), ausencia de protocolos, también de exámenes de laboratorio para Covid-19, incluso espacios físicos. Todo ello les hace percibir que la atención de las mujeres es el eslabón olvidado del sistema de salud. Las aseveraciones siguientes se refieren a ello: «Al comienzo de la pandemia no tuvimos orientaciones respecto a la continuidad de la atención de las gestantes» (E-5); «Sin embargo esto ha sido insuficiente en la atención de nuestra población objetivo ya sea por priorizar otros servicios clínicos en cuanto a distribución de EPP y enfoques de protocolos, así como también en los espacios y manejos destinados a nuestras pacientes» (E-17).

A su vez enfatizan falencias que podrían interferir en el desarrollo de las actividades, como asimismo poner en riesgo a las propias usuarias. «[...] hemos tenido que imponernos para conseguir que nos entreguen las EPP adecuadas» (E-2). «Los EPP han sido muy escaso en mi zona de trabajo, teniendo que reciclar muchos o utilizar uno lo que más se pueda atendiendo más de 3-4 pacientes» (E-13); «Actualmente encuentro que son escasas las medidas de prevención al salir a terreno, y además de priorizar a solo gestantes» (E-4). «En cuanto a lo que ha sucedido en mi hospital, aun seguimos teniendo días en que nos faltan insumos básicos y también de EPP, teniendo a veces que recurrir a compras personales» $(\mathrm{E}-16) ;$ «[...] en mi centro de salud no se ha priorizado la atención de la mujer, lo cual dificulta poder entregar las prestaciones de forma segura»(E-1). «Tengo un sitio en Facebook y casi todas las consultas a nivel país se refieren al abandono de los métodos anticonceptivos, por falta de controles habituales y recetas, considero un tema fundamental y urgente a reforzar» $(\mathrm{E}-7)$.

\section{Tema 2: Cuidados y Prioridades en la Atención de Matronería}

\section{Categoría 1: Cuidados de la Atención en Salud sexual y reproductiva}

Surge de la percepción las/los participantes, acerca de las actividades del quehacer de la Matronería y los sentimientos que nacen en los procesos de atención a usuarias.

\section{Subcategoría «Prestaciones entregadas»}

Básicamente se refiere a las actividades del quehacer profesional realizadas durante la pandemia y las prioridades que establecieron, según los diferentes espacios laborales. Matronas y matrones participantes señalan que los cuidados que han priorizado son los 
controles a mujeres gestantes, recién nacido y puérperas, tanto en nivel primario como terciario. Luego o en un mismo momento y según campo laboral, han entregado los controles de métodos anticonceptivos. Algunas aseveraciones en este sentido son: «[...] se ha priorizado la atención en domicilio de las gestantes y control díada» (E-3); «[...] las matronas estamos respondiendo a necesidad ingresos prenatales, control diadas, pesquisa estreptococos, recetas de anticonceptivos por 6 meses» (E-4). También señalan el cambio de la modalidad para la entrega de la atención: «Además de las teleconsultas, sobre todo para lo de planificación familiar» (E-6).

Los profesionales de la Matronería señalan que las actividades de urgencia es una demanda que no se ha detenido, independientemente de contar con EPP o protocolos. Tanto en el principal hospital de la región como en otros hospitales y establecimientos de APS, las atenciones continuaron desarrollándose: «En este sentido hemos priorizado horas ARO [Alto Riesgo Obstétrico] y hemos mantenido las atenciones de urgencia como siempre» (E-14); «Con respecto a la atención de la mujer, se han mantenido las atenciones de urgencias y parto, tomando medidas de protección acordes» (E-12).

\section{Subcategoría «Sentimientos y emociones»}

Se genera a partir de la vivencia que matronas y matrones relatan desde el inicio de la pandemia, vivencias con mucho miedo, pero también entendiendo que debían seguir cumpliendo con su deber profesional, constituyéndose como una experiencia laboral al límite de su resistencia emocional. Algunas afirmaciones son: «[...] Hay semanas que colapso, pero solo para mí, no exteriorizo, ante todo hay que mantener la calma por nuestras usuarias (E-15); «Considero que, a pesar de estar en primera línea, no se ha valorado el esfuerzo personal para cumplir a cabalidad con las funciones asignadas como Matrón/a» (E-17).

Consecuentemente con lo expresado, las/los profesionales de la Matronería manifiestan sentirse entre el miedo y el deber, así lo refieren algunas aseveraciones: «Cada funcionario, según mi experiencia, ha experimentado sensación de miedo y angustia, pero entre nosotros mismos, intentamos mantener la calma para seguir combatiendo esta pandemia» (E-3); «Mucha gente está comprometida con su trabajo, pero el miedo es un factor que dificulta las actividades» (E-10). 
La relación con la familia es otro elemento que genera temores y sentimientos, algunas afirmaciones son: «[...] sigue la incertidumbre y estrés diario en contagiarse y contagiar a mi familia» (E-14).

También se observa un sentimiento relacionado con la valoración del quehacer profesional desarrollado, donde a veces es ignorado por las autoridades del sistema de salud: «[...] a todos nos hace bien escuchar que lo estamos haciendo bien y que estamos aportando con nuestro trabajo y sacrificio. Nunca hablan de nosotros matronas y gines [ginecólogos] desde el nivel central, no nos consideran primera línea» (E-3).

\section{Categoría 2: Gestión del Cuidados de la Atención en Salud sexual y reproductiva}

Esta categoría se refiere a las acciones implementadas desde la Matronería, como la ejecución de nuevos planes de atención, coordinación con otros profesionales y en general reorganizar la atención entregada.

\section{Subcategoría "Manejo profesional autónomo»}

Esta subcategoría surge de la vivencia de matronas y matrones principalmente al inicio de la pandemia, donde coinciden en el caos que vivenciaron. Consecuentemente debieron evaluar la realidad de su establecimiento y tomar decisiones según la realidad local, con el propósito de mantener las actividades profesionales, sin poner en riesgo a las usuarias y tampoco al equipo de salud. Para ello debieron reorganizar la atención profesional en salud sexual y salud reproductiva: «[...] nuestro trabajo ha sido autónomo, según nuestro criterio y tomando todas las precauciones necesarias» (E-1); «[...]el equipo de Matronería ha logrado una buena reorganización de sus actividades clínicas y administrativas, resguardando la salud tanto del equipo de profesionales y de nuestras usuarias» (E-10).

\section{Subcategoría «Gestión para prevenir riesgos»}

Se refiere a las coordinaciones y comunicaciones que matronas y matrones debieron realizar con las jefaturas de los servicios y con otras unidades, con el objeto de mantener las atenciones en salud sexual y reproductiva. También se reconoce el aprendizaje que esta pandemia ha obligado y la aplicación de medidas cuyos resultados satisface el desarrollo profesional, evidencia la capacidad de gestión del estamento profesional para cuidar la salud de las usuarias, se suma la siguiente afirmación: «No pasa por una política institucional sino por el compromiso de las matronas por cuidar, a toda costa, a las mujeres» (E-8). 
También se observa un énfasis en los aprendizajes profesionales adquiridos y su posible impacto en una mejor conducta profesional futura, además de los esfuerzos para mantener la entrega de los cuidados inherentes al tipo de usuarias: «También es cierto que constantemente aprendemos que hay oportunidades de mejora en los nuevos procesos, y que de los errores hay que sacar aprendizajes y corregir» (E-2); «[...] Podemos dar fe de que nuestra población no se ha quedado sin MAC [métodos anticonceptivos], pero ha sido un arduo trabajo y muy agotador» (E-7).

Otros aspectos que relatan las/los profesionales de la Matronería refiere a su trabajo frente a usuarias con Covid-19, además del trabajo colaborativo con el establecimiento de salud donde laboran: «[...] no se ha registrado gran número de usuarias COVID positivo y las pocas han tenido evolución positiva, sin contagio de su recién nacido» (E9); «[...] en el CESFAM que trabajo he tenido que hacer labores de matrona, laboratorio, gestiones de transporte y aprender a utilizar máquinas como centrífuga en laboratorio» (E- 18)

Finalmente, se observa además una cierta complacencia con la respuesta de las usuarias y los vínculos de coordinación y comunicación con instancias administrativas que les hace percibir un deber profesional cumplido. Algunas afirmaciones en este sentido son: «Referente a las atenciones clínicas, hemos priorizado y nuestras usuarias lo han entendido» (E-1); «Desde la Matronería, se ha intentado resguardar la vida de las usuarias en todo momento, modificando nuestras atenciones tanto en atención abierta como cerrada» $(\mathrm{E}-17)$.

\section{DISCUSIÓN}

Ante la pregunta ¿cómo se enfrentan los cuidados de salud sexual y reproductiva en el sistema de salud chileno en el contexto de pandemia, desde la perspectiva de los profesionales de la Matronería, desde La Araucanía?, surgen respuestas a partir del análisis de los discursos de las entrevistadas que permitirían inferir que, debido al manejo general de la pandemia, ocurre una postergación de los cuidados de la salud sexual y reproductiva de las mujeres, lo que no es ajeno a otras realidades latinoamericanas (Damián López, 2020), produciéndose una invisibilización tanto de quienes generan el cuidado como de quienes lo reciben. Este mismo discurso se encuentra plasmado en noticias referentes a la temática donde el colegio de matronas y matrones piden al Gobierno no olvidar a las gestantes (Casas, 2020), solicitando además protocolos de 
acción para la protección de mujeres y profesionales (Castillo, 2020), y considerar a las gestantes como población de riesgo en esta pandemia (El desconcierto, 2020).

Dicho fenómeno se sustenta al parecer en las lógicas patriarcales de las políticas públicas, que se encarna en las prácticas de salud, dirigidas a la población en general y las mujeres en lo particular (UNFPA, 2020). Dentro del discurso de las/os entrevistadas/os, se aprecia una naturalización de esta práctica, al mantener una tolerancia al abandono frente a las nuevas problemáticas emergentes, asentando su actuar en lo que denomina espíritu de servicio, y que desde una perspectiva crítica a la feminización del sujeto que contribuye al cuidado del otro o la otra, en este caso, lo denominamos la domesticación del trabajo (Pastor Gosálbez, Belzunegui Eraso y Pontón Merino, 2012; Palomo, 2009; Haraway, 1995).

Desde la percepción de los entrevistados y entrevistadas, los cuidados otorgados por la matronería en el contexto de pandemia configuran una transformación de las prestaciones de salud sexual y salud reproductiva, consistente en el retraso y la postergación de las horas programadas, exámenes de PAP, VIH, entre otros, como lo plantea el III informe de la Corporación Miles (Corporación Miles, 2021), que están normalizadas y programadas de forma constreñida por las políticas del sistema de salud, lo que plantea la eventualidad de apertura a nuevas posibilidades de mantenimiento de vínculo con las mujeres, compartir junto a ellas y con ellas un intercambio en el espacio de los cuidados (Tronto, 1993).

Llama la atención el juicio evaluador de las conductas del otro/a, en lo que respecta a las actitudes del sujeto que no forma parte de los equipos de salud, atribuyéndole a su irresponsabilidad las consecuencias de una pandemia mal manejada por el sistema y las autoridades, como plantea la categoría «manejo de la pandemia», develando así la subjetividad patriarcal y neoliberal (Ortiz Gómez, 2014) que justifica la negligencia de la autoridad y naturaliza las respuestas extraordinarias de los sujetos en la vida cotidiana.

Dada la feminización del trabajo en salud (Petrone, 2018; Pastor Gosálbez, Belzunegui Eraso y Pontón Merino 2012), principalmente en salud sexual y salud reproductiva, se podría inferir que, en este ámbito laboral, se cumple el supuesto de que las mujeres que cuidan a mujeres conforman el eslabón olvidado del sistema de salud, lo que expone los cuerpos y la salud de las mujeres cuidadas, y en la misma medida vulnera y explota a las mujeres que cuidan. 
Todo lo señalado anteriormente, tanto en relación con la crisis social que es previa a la crisis sanitaria, observamos nuevamente como el Estado neoliberalizado se repliega ante la necesidad de los cuidados en salud sexual, salud reproductiva y salud perinatal, y que prescinde de otorgarlos por no considerarlos esenciales en esta lógica de devaluación, feminización y domesticación, donde además las profesionales de la matronería, a pesar de la nula respuesta del sistema de salud, reorganizan sus funciones, sus prácticas, dialogando con las mujeres y sus necesidades, para mantener el cuidado y el vínculo.

\section{CONCLUSIONES}

Se observa desde el relato de las y los entrevistadas/os que la posición de la profesional de salud a día de hoy es problemática, donde, por un lado, se percibe como la institucionalidad, configurada por el Ministerio de Salud y los niveles superiores de toma de decisiones, no entrega directrices, ni la información clara acerca de que se debería hacer en relación con el cuidado en salud sexual y reproductiva por el contexto de pandemia. Por otro lado, este mismo profesional se ve enfrentado a las demandas de la población, siendo las mujeres las más desprotegidas, ya que no son consideradas como prioritarias por el sistema de salud.

Ante tal replegamiento del sistema de salud, las profesionales transforman sus prácticas de cuidado, reorganizan las prestaciones y priorizan en relación a las necesidades de las mujeres; inclusive convierten el espacio doméstico en una suerte de prolongación del espacio institucionalizado del centro de salud, profundizando la principal estrategia del modelo de salud familiar; es así como el cuidado en matronería emerge como una práctica de respuesta a las necesidades de las mujeres ante la crisis sanitaria de la COVID-19.

La ausencia de directrices desde el sistema no es lo único sentido por las profesionales, sino que, además, se relata cierta sensación de abandono, que estructura sentimientos y emociones, que se agudizan en el contexto de pandemia; temores emergen en las profesionales que sin duda afectan su salud mental.

Desde el relato, se desprende que la salud sexual y salud reproductiva, desde el sistema de salud, no ha sido tomada en cuenta, hegemonizándose la acción de urgencia y todas las acciones tendientes al diagnóstico y terapéutica de la COVID-19, concentrándose en la hospitalización de alta complejidad, por lo que se concluye que los cuidados de la salud sexual y salud reproductiva siempre han estado invisibilizados en la «domesticación de su entrega» y altamente feminizados, lo que los hace prescindibles por el sistema de salud. 


\section{BIBLIOGRAFÍA}

Berteaux, D. Los relatos de vida. Perspectiva etnosociológica. Barcelona: Ediciones Bellaterra, 2005.

BINFA, L., et al. Chilean midwives and midwifery students' views of women's midlife health-care needs. En: Midwifery. 2011, vol. 27, núm. 4, pp. 417-423.

BINFA, L., et al. Assessment of the implementation of the model of integrated and humanised midwifery health services in Chile. En: Midwifery. 2016, vol. 35, pp. 5361.

CASAS, L. Matronas piden al Gobierno no olvidar situación de embarazadas durante la pandemia. En: Biobiochile.cl. 2020. [Consulta: 9 de junio de 2020]. Disponible en: https://bit.ly/3GIpRpy.

Castillo, J. C. Colegio de Matronas pidió al Gobierno firmar protocolo de acción para el cuidado de los profesionales y las mujeres. En: ADN Radio.cl. 2020. [Consulta: 9 de junio de 2020]. Disponible en: https://bit.ly/3FujGUs.

ChARMAZ, K. La teoría fundamentada en el siglo XXI. Aplicaciones para promover estudios sobre la justicia social. Manual de investigación cualitativa. Barcelona: Gedisa, 2013, pp. 198-227.

Clarke, A. E. Situational Analysis: Grounded Theory After the Postmodern Turn. Londres: SAGE, 2005.

Colegio Médico De ChIle. Primer informe COVID-19. Departamento de Políticas de Salud y Estudios. 2020. [Consulta: 4 de mayo de 2021]. Disponible en: https://bit.ly/3Kj7dqf.

CORPORACIÓN MiLES. Tercer Informe sobre Derechos, Salud Sexual y Reproductiva y Violencia de Género en Chile by Corporación Miles Chile. Santiago: 2021. [Consulta: 26 de mayo 2021]. Disponible en: https://bit.ly/3Km7Src.

Creswell, J. W.; Creswell, J. D. Research design: qualitative, quantitative, and mixed methods approaches. Londres: SAGE, 2018.

Creswell, J. W.; Poth, C. N. Qualitative inquiry and research design: Choosing among five traditions. Londres: SAGE, 2018.

DAMIÁN LÓPEZ, B. La salud sexual y reproductiva en tiempos de COVID-19 en el Perú. En: Revista Médica Basadrina. 2020, vol. 14, núm. 1, pp. 56-58.

El DesCONCIERTO. Colegio de Matronas: «Embarazadas no son consideradas población de riesgo en la pandemia». 2020. [Consulta: 9 de junio de 2020]. Disponible en: https://bit.ly/3I9us4j.

GAMBLE, J., et al. Acknowledging the primacy of continuity of care experiences in midwifery education. En: Women and Birth. 2020, vol. 33, núm. 2, pp. 111-118.

HARAWAY, D. Ciencia, cyborgs y mujeres La reinvención de la naturaleza. Madrid: Ediciones Cátedra, 1995. 
Homedes, N.; UgAlde, A. Privatización de los servicios de salud: las experiencias de Chile y Costa Rica. En: Gaceta Sanitaria. 2002, vol. 16, núm. 1, pp. 54-62.

Hu, D., et al. 2020. Frontline nurses' burnout, anxiety, depression, and fear statuses and their associated factors during the COVID-19 outbreak in Wuhan, China: A largescale cross-sectional study. En: EClinicalMedicine. 2020, vol. 24, p. 100424.

INE - Instituto Nacional De Estadísticas. Resultados CENSO 2017. Chile: Gobierno de Chile, 2017. [Consulta: 4 de mayo de 2021]. Disponible en: https://bit.ly/3GBs1qV.

KANG, L., et al. Impact on mental health and perceptions of psychological care among medical and nursing staff in Wuhan during the 2019 novel coronavirus disease outbreak: A cross-sectional study. En: Brain, Behavior, and Immunity. 2020, vol. 87, pp. 11-17.

LABRA, M. E. La reinvención neoliberal de la inequidad en Chile: el caso de la salud. En: Cadernos de Saúde Pública. 2002, vol. 18, núm. 4, pp. 1041-1052.

LAI, J., et al. Factors Associated With Mental Health Outcomes Among Health Care Workers Exposed to Coronavirus Disease 2019. En: JAMA network open. 2020, vol. 3, núm. 3, p. e203976.

Lillo, E., et al. Midwifery in Chile - A Successful Experience to Improve Women's Sexual and Reproductive Health: Facilitators \& Challenges. En: Journal of Asian Midwives [en línea]. 2016, vol. 3, núm. 2, pp. 48-55.

LU, W., et al. Psychological status of medical workforce during the COVID-19 pandemic: A cross-sectional study. En: Psychiatry Research. 2020, vol. 288, p. 112936.

Macdorman, M. F.; Singh, G. K. Midwifery care, social and medical risk factors, and birth outcomes in the USA. En: Journal of Epidemiology \& Community Health. 1998, vol. 52, núm. 5, pp. 310-317.

Mathias, L.A.; DAVIS, D.; Ferguson, S. Salutogenic qualities of midwifery care: A best-fit framework synthesis. En: Women and Birth. 2020, vol. 34, núm. 3, 266-277.

Ministerio De Desarrollo Social. Situación de pobreza, sintesis de resultados encuesta CASEN. Encuesta de Caracterización Socioeconomica Nacional (CASEN). Chile: Gobierno de Chile, 2017. [Consulta: 4 de mayo de 2021]. Disponible en: https://bit.ly/3KgR98y.

Ministerio De SALUD. Sobre la investigacion cientifica en el ser humano, su genoma, y prohibe la clonacion humana. Chile: Gobierno de Chile, 2006. Disponible en: http://bcn.cl/2fe0y.

Ministerio De SAlud. Regula los derechos y deberes que tienen las personas en relación con acciones vinculadas a su atención en salud. Chile: Gobierno de Chile, 2012. Disponible en: http://bcn.cl/2f7cj. 
Ministerio De SAlud. Ministerio de Salud anuncia cuarentena total para Temuco y Padre las Casas. Chile: Gobierno de Chile, 2020 [Consulta: 4 mayo 2021]. Disponible en: https://bit.ly/3fue1Dp.

MIRA, A. Crisis de representatividad y estallido social: Una aproximación a la actual experiencia chilena. En: Polis. Revista Latinoamericana. 2011, vol. 10, núm. 30, pp. 185-197.

Morin, E. Introducción Al Pensamiento Complejo. Barcelona: Gedisa, 2019.

OMS - ORganización Mundial De LA SAlud. Preguntas y respuestas sobre la enfermedad por coronavirus (COVID-19). 2020. Disponible en: https://bit.ly/3nxnAWD.

OrTiz Gómez, M. G. El perfil del ciudadano neoliberal: la ciudadanía de la autogestión neoliberal. Sociológica (México). 2014, vol. 29, núm. 83, pp. 165-200.

Palomo, M. T. M. Domesticar el trabajo: una reflexión a partir de los cuidados. En: Cuadernos de Relaciones Laborales. 2009, vol. 26, núm. 2, pp. 13-44.

Pastor Gosálbez, M. I.; Belzunegui Eraso, Á.; Pontón Merino, P. Mujeres en sanidad: entre la igualdad y la desigualdad. En: Cuadernos de Relaciones Laborales. 2012, vol. 30, núm. 2, pp. 497-518.

Petrone, P. La feminización en la Medicina. En: Revista Colombiana de Cirugía. 2018, vol. 33, núm. 2, pp. 132-134.

Powell Kennedy, H. The essence of nurse-midwifery care The woman's story. En: Journal of Nurse-Midwifery. 1995, vol. 40, núm. 5, pp. 410-417.

RENFREW, M. J., et al. Sustaining quality midwifery care in a pandemic and beyond. En: Midwifery. 2020, vol. 88, p. 102759.

Requena, A.; CARrero, V.; SORIANO, R. M. Teoría fundamentada «Grounded theory»: la construcción de la teoría a través del análisis interpretacional. Madrid: Centro de Investigaciones Sociológicas, 2006.

Silva-PEÑA, I.; PAZ-MALdONAdO, E. Formación docente para la justicia social desde la perspectiva emocional: Indagaciones narrativas en el contexto de la revolución del torniquete. En: Revista Interuniversitaria de Formación del Profesorado. 2019, vol. 33, núm. 3, pp. 195-212.

Tronto, J. C. Moral Boundaries: A Political Argument for an Ethic of Care. London: Routledge, 1993

UnfPa - Fondo De Población De Naciones Unidas. COVID-19: un enfoque de género. Proteger la salud y los derechos sexuales y reproductivos y promover la igualdad de género. Marzo de 2020. Disponible en: https://bit.ly/3GDhxXN.

ZERBINI, G., et al. Psychosocial burden of healthcare professionals in times of covid-19 - a survey conducted at the university hospital augsburg. En: GMS - German Medical Science. 2020, vol. 18, pp. 1-9. 